\title{
REPLY
}

\section{Component age estimates for the Hell Gap Paleoindian site and methods for chronological modeling of stratified open sites - Response to commentary by C. Vance Haynes}

\author{
Spencer R. Pelton ${ }^{\mathrm{a}, *}$, Marcel Kornfeld ${ }^{\mathrm{b}}$, Thomas Minckley ${ }^{\mathrm{c}}$, Mary Lou Larson ${ }^{\mathrm{b}}$ \\ ${ }^{\mathrm{a} D e p a r t m e n t ~ o f ~ A n t h r o p o l o g y, ~ U n i v e r s i t y ~ o f ~ W y o m i n g, ~ 12 t h ~ a n d ~ L e w i s ~ S t ., ~ D e p a r t m e n t ~ 3431, ~} 1000$ E. University Avenue, Laramie, Wyoming 82071, USA \\ bepartment of Anthropology, Paleoindian Research Lab, University of Wyoming, 12th and Lewis St., Department 3431, 1000 E. University Ave., \\ Laramie, Wyoming 82071, USA \\ ${ }^{c}$ Department of Geography, University of Wyoming, 207 Arts and Sciences Building, Department 3371, 1000 E University Ave. Laramie, Wyoming 82071, USA
}

We appreciate the dialog initiated by Haynes regarding the Hell Gap chronology and, more broadly, how to apply age modeling to terrestrial stratigraphic sequences. Chronological approaches such as ours are relatively new to archaeology and, as such, have yet to demonstrate their utility as accurate means of estimating archaeological ages. We appreciate Haynes' diligence in calling to attention potential complications with our approach, especially those related to variable sediment package morphology between depositional agents (i.e., overbank versus hillslope deposition).

Hayne's (2017, p. 1) chief criticism is that we assume the stratigraphic position of the Goshen occupation at Hell Gap, citing a recent publication that asserts it is difficult to separate from an overlying Folsom component (Haynes and Hill, 2017, pp. 256-257). We acknowledge the difficulty of separating the components, but note that Irwin (1968) was able to at both localities I and II of Hell Gap, that the vertical position of Goshen below Folsom is clearly indicated in a 1966 profile (Kornfeld and Larson, 2009, fig. 1.6), and that the positions of the Goshen (mode 11) and Folsom (modes 8-10) components (Fig. 1, right side) are indeed possible to separate by around $12 \mathrm{~cm}$, though they likely grade into each other through vertical artifact dispersal.

Recent field results combined with reevaluation of diagnostic Goshen point provenience confirm our (Pelton et al., 2017) interpretation of Goshen's stratigraphic position. Specifically, one Goshen point (UWI-336) was recovered only $66 \mathrm{~cm}$ south of our (Pelton et al., 2017) artifact sample, so it is likely directly related to our artifact density modes (Bradley, 2009). This Goshen point corresponds to an elevation of $97.11 \mathrm{~m}$ in the current datum coordinates, which is only $1 \mathrm{~cm}$ lower than our lowest artifact mode 11, located at an elevation of $97.12 \mathrm{~m}$.

* Corresponding author at: Department of Anthropology, University of Wyoming, 12th and Lewis St., Department 3431, 1000 E. University Ave., Laramie, Wyoming 82071, USA. E-mail address: spencerpelton@gmail.com (S. Pelton).
Thus, we remain confident in our age estimate of ca. $12,800 \mathrm{cal}$ yr BP for Goshen artifacts at Hell Gap.

In the remainder of this reply, we address details of Haynes' qualitative assessment of radiocarbon dates by: (a) revising the Pelton et al. (2017) model based on Haynes' revised locations in his comment of four radiocarbon dates; and (b) conducting a systematic comparison of Haynes' preferred dates for Locality I and the original Pelton et al. (2017) model.

In his comment, Haynes assigned two dates (AA-28774 and AA-28775) to a different substratum than Pelton et al. (2017) and helped to clarify the position of sample 6HG93 from which two dates were determined (AA-14434 and AA-33671). Adjusting for Haynes' positions using the age-depth correction procedure in Pelton et al. (2017), AA-28774 is located $32 \mathrm{~cm}$ lower at a standardized elevation $\left(Z_{\mathrm{st}}\right)$ of $208 \mathrm{~cm}$ below ground surface (bgs), AA-28775 is located $35 \mathrm{~cm}$ lower at a $Z_{\mathrm{st}}$ of $218 \mathrm{~cm}$ bgs, and sample $6 \mathrm{HG} 93$ is located $29 \mathrm{~cm}$ higher at a $Z_{\mathrm{st}}$ of $277 \mathrm{~cm}$ bgs. We repeated the procedures outlined in Pelton et al. (2017) and re-estimated the ages of the Locality I components based on these revised positions. The revised model contains 22 radiocarbon dates compared to our original 21. It includes 20 dates present in the original model, omits one date from the original model (AA-28775), and adds two older dates based largely on the adjusted position of sample 6HG93 (AA-33671 and AA-27646).

The revised model changed our age estimates most for the Hell Gap (mode 6) and Agate Basin (mode 7) components by ca. 550 and $420 \mathrm{yr}$, respectively (Fig. 1; Table 1). These younger estimates are a result of moving date AA-28774 one substratum lower to $\mathrm{E}_{3}$, per Haynes' recommendation. We reiterate our statement from Pelton et al. (2017, supplementary material), however, that date AA-28774 is from a convoluted section of Locality I West with several uncertain stratigraphic contacts, and that our original stratigraphic assignment may remain valid. Our original age estimates are certainly more consistent with dates from other Agate Basin and Hell Gap sites (Pelton et al., 2017, table 4). Encouragingly, all other revised age estimates are 


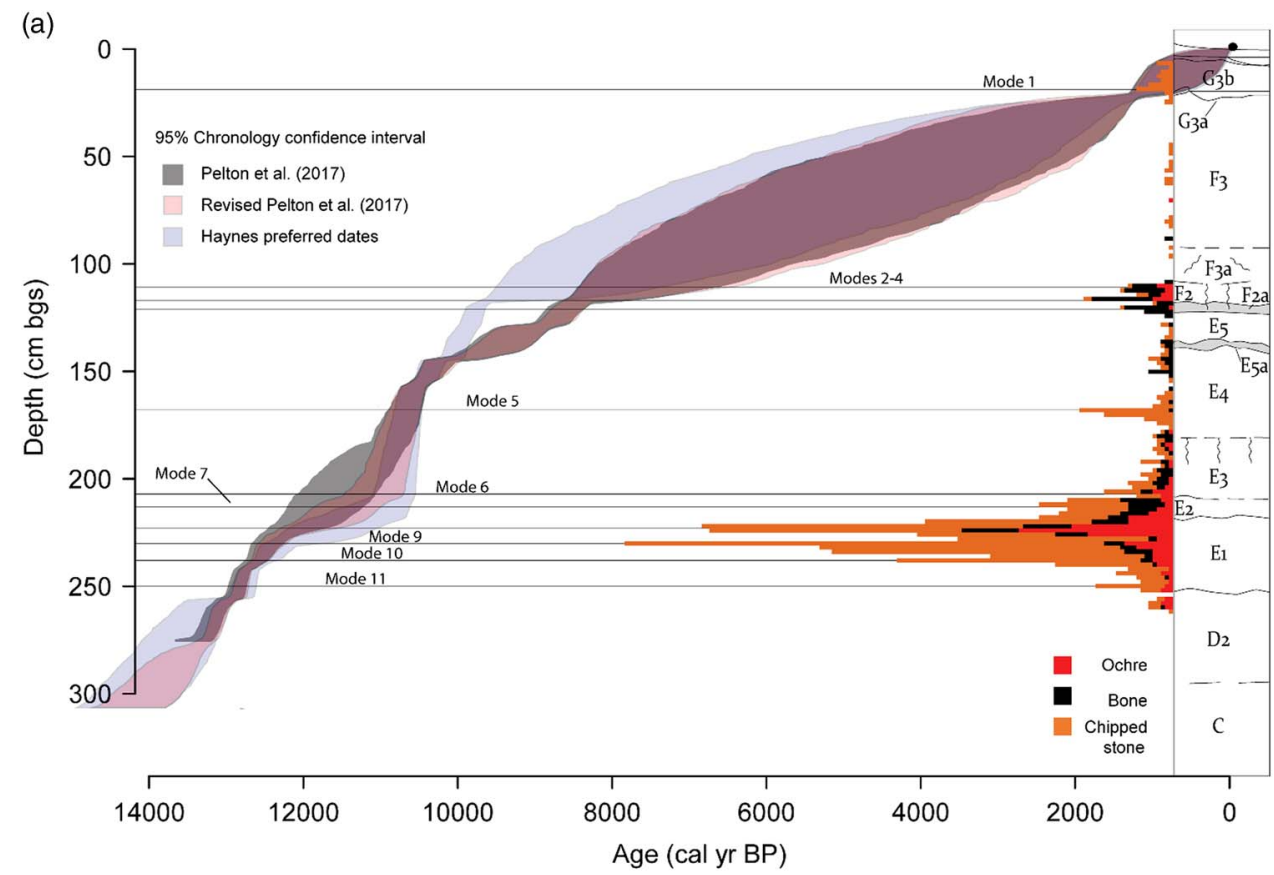

(b)

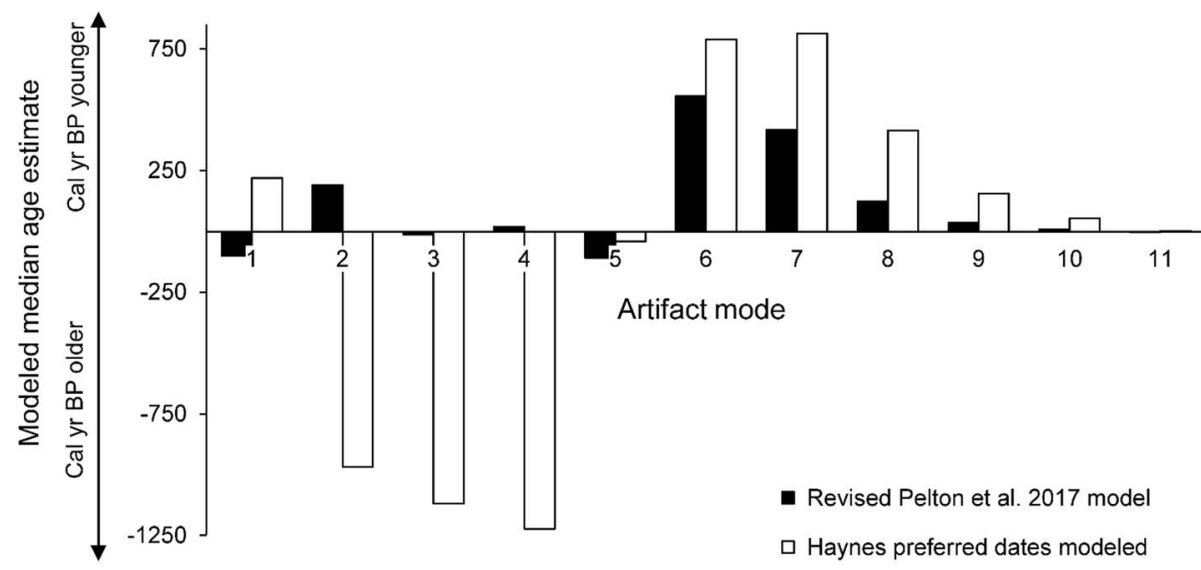

Figure 1. (color online) Comparison of the Pelton et al. (2017) model with the revised Pelton et al. (2017) model and a model based on Haynes' preferred dates for Hell Gap Locality I. (a) A graphic comparison of the age-depth model probability regions. (b) A systematic comparison of the modeled median age estimates for each artifact frequency mode.

comparable to our original model, especially for the earliest three artifact modes 9, 10, and 11, whose median age estimates are only 35,8 , and $3 \mathrm{yr}$ different than the median age estimates of our original model, respectively. All other median age estimates fall well within the range of uncertainty subsumed by the age estimates presented in Pelton et al. (2017).

Next, we address Haynes' qualitatively preferred dates for Locality I. Rather than discussing individual radiocarbon dates with which Haynes is certainly more familiar, we present a model using the Pelton et al. (2017) methods combined with Haynes' preferred dates to determine how much difference it makes to impose qualitative vetting prior to modeling (Fig. 1).

The most encouraging aspect of this comparison is that Haynes' preferred dates produce median age estimates for the Folsom (modes 9 and 10) and Goshen (mode 11) components only 156, 53, and 1 yr younger than those presented by Pelton et al. (2017). Haynes' preferred dates produce comparatively young median age estimates for the late Folsom (mode 8), Agate Basin (mode 7), and Hell Gap (mode 6) components of ca. 410,810 , and $790 \mathrm{yr}$, respectively. Again, this is partly due to placing radiocarbon dates AA-28774 and AA-28775 in substratum $E_{3}$, rather than $E_{4}$. Our median age estimates for the Alberta component are similar, differing by only ca. $40 \mathrm{yr}$.

Haynes' preferred dates for the Frederick component produce far older age estimates because they are 1000 to $1500 \mathrm{yr}$ older than the dates from stratum $\mathrm{F}$ included in the Pelton et al. (2017) model. Haynes' preferred dates were omitted from our model as outliers because they were higher and older than expected given all age-depth probability estimates for Locality I. 
Table 1. Revised Pelton et al. (2017) age estimates based on the repositioning of three dates per Haynes' commentary.

\begin{tabular}{|c|c|c|c|c|c|c|}
\hline $\begin{array}{l}\text { Artifact mode/ } \\
\text { archaeological } \\
\text { culture }\end{array}$ & Min & $\begin{array}{c}1 \text { st } \\
\text { quartile }\end{array}$ & Median & Mean & $\begin{array}{c}\text { 3rd } \\
\text { quartile }\end{array}$ & $\operatorname{Max}$ \\
\hline 1/Late Prehistoric & -17 & 1085 & 1121 & 1116 & 1150 & 2401 \\
\hline 2/Frederick & 6356 & 7496 & 7689 & 7753 & 8078 & 8595 \\
\hline 3/Frederick & 8002 & 8341 & 8398 & 8393 & 8456 & 8767 \\
\hline 4/Frederick & 8226 & 8468 & 8526 & 8527 & 8585 & 8877 \\
\hline 5/Alberta & 10,331 & 10,619 & 10,689 & 10,690 & 10,761 & 11,527 \\
\hline 6/Hell Gap & 10,557 & 10,966 & 11,017 & 11,016 & 11,055 & 12,143 \\
\hline 7/Agate Basin & 10,707 & 11,230 & 11,332 & 11,356 & 11,452 & 12,314 \\
\hline 8/Folsom-Midland & 11,293 & 11,871 & 11,990 & 11,973 & 12,104 & 12,415 \\
\hline 9/Folsom & 11,993 & 12,345 & 12,417 & 12,409 & 12,480 & 12,649 \\
\hline 10/Folsom & 12,344 & 12,546 & 12,592 & 12,584 & 12,630 & 12,713 \\
\hline 11/Goshen & 12,644 & 12,773 & 12,803 & 12,808 & 12,840 & 13,027 \\
\hline
\end{tabular}

Although Haynes has reasonable rationale for rejecting the younger dates from stratum $\mathrm{F}$, we are currently reluctant to disregard the Pelton et al. (2017) age estimates for Frederick. Our age estimates may be on the young end of known Late Paleoindian components, but not unreasonably so. Qualitative radiocarbon date assessment may sometimes result in circular reasoning, wherein dates that fit existing chronologies are preferred to those that do not and conflicting dates are attributed solely to contamination or mixing. The way our study dealt with the conflicting dates from stratum $\mathrm{F}$ is a good example of the way in which probabilistic modeling can help identify and objectively resolve such issues independent of subjective assessment.

To conclude, all age-depth models are inaccurate to varying degrees (Trachsel and Telford, 2017), but so are most radiocarbon dates due to contamination, mixing, old wood, and other problems related to estimating the ages of phenomena that occurred thousands of years ago. In this case and others, age-depth modeling is not about discovering an absolute "truth," but rather about clarifying complex geomorphic situations objectively and as accurately as possible. While archaeological understanding of the potential inaccuracies inherent to radiocarbon dating has improved considerably, the imposition of non-systematic judgments of radiocarbon date quality has the potential to result in circular reasoning if undertaken frivolously and in accord only with one's pre-existing expectations. Haynes has worked on the Hell Gap site for many decades and likely possesses the nuanced knowledge of potential contamination sources and site-specific formation required to undertake qualitative assessment of its chronology, but we remain wary of statements that dates are, for instance, "probably...translocated," "too young by comparison" to nearby dates, or "anomalously old." Age-depth models constrain the inaccuracies inherent to radiometric age estimation largely independent of subjective judgments of quality and are thus more easily replicable by future researchers working at Hell Gap and other stratified open sites.

\section{REFERENCES}

Bradley, B.A., 2009. Appendix K: Data, codes, and descriptions used in projectile point and biface analysis. In: Larson, M.L., Kornfeld, M., Frison, G.C. (Eds.), Hell Gap: A Stratified Paleoindian Campsite at the Edge of the Rockies. University of Utah Press, Salt Lake City, pp. 414-422.

Haynes, C.V. Jr., Hill, M.E., 2017. Plainview-Goshen-Midland typological problems. In: Holliday, V.T., Johnson, E., Knudson, R. (Eds.), Plainview: The Enigmatic Artifact Style of the Great Plains. University of Utah Press, Salt Lake City, pp. 249-273.

Irwin, H., 1968. The Itama: early Late-Pleistocene inhabitants of the Plains of the United States and Canada and the American Southwest. PhD Dissertation, Department of Anthropology, Harvard University, Cambridge.

Kornfeld, M., Larson, M.L., 2009. Reinvestigation in context: Paleoindian prehistory at the edge of the Rockies. In: Larson, M. L., Kornfeld, M., Frison, G.C. (Eds.), Hell Gap: A Stratified Paleoindian Campsite at the Edge of the Rockies. University of Utah Press, Salt Lake City, pp. 3-13.

Pelton, S.R., Kornfeld, M., Larosn, M.L., Minckley, T., 2017. Component age estimates for the Hell Gap Paleoindian site and methods for chronological modeling of stratified open sites. Quaternary Research 88, 234-247.

Trachsel, M., Telford, R.J., 2017. All age-depth models are wrong, but they are getting better. The Holocene 27, 860-869. 